\title{
Best Jobs 2014
}

\section{by the Editors}

A mathematical education is more important for today's workplace than ever before. The concepts of mathematics permeate physics, fluid dynamics, atmospheric science, economics, and biology. Mathematical disciplines such as game theory, stochastic calculus, and cryptography find ever-broader applicability in the workplace.

Careers in mathematically oriented fields rank among the most desirable and best-paying-with "mathematician" topping the bill—in the "2014 Jobs Rated" report published by job-search website careercast.com ${ }^{1}$, and cited in an online article by Adam Auriemma in the Wall Street Journal. ${ }^{2}$ The report ranks mathematician, statistician, and computer systems analyst among the 10 best mid-level income jobs of 2014. Two hundred types of jobs were studied and compared with regard to workplace environment, pay, and potential for the future. ${ }^{3}$

Here are the 10 best mid-level income jobs of 2014 (with their median annual salaries) according to the report.

1. Mathematician / $\$ 101,360$

2. Tenured University Professor / $\$ 68,970$

3. Statistician $/ \$ 75,560$
4. Actuary / $\$ 93,680$

5. Audiologist / $\$ 69,720$

6. Dental Hygienist $/ \$ 70,210$

7. Software Engineer / $\$ 93,350$

8. Computer Systems Analyst / $\$ 79,680$

9. Occupational Therapist / $\$ 75,400$

10. Speech Pathologist / $\$ 69,870$

Incidentally, the report ranked the following as the 10 worst mid-level income jobs of $2014:^{4}$

200. Lumberjack / $\$ 24,340$

199. Newspaper Reporter / $\$ 37,090$

198. Enlisted Military Personnel / $\$ 28,840$

197. Taxi Driver / $\$ 22,820$

196. Broadcaster / $\$ 55,380$

195. Head Cook / $\$ 42,480$

194. Flight Attendant / $\$ 37,240$

193. Garbage Collector / $\$ 22,970$

192. Firefighter / $\$ 45,250$

191. Corrections Officer / $\$ 38,970$

\footnotetext{
${ }^{1}$ Kyle Kensing, “The Best Jobs of 2014”, http://www.careercast.com/jobs-rated/best-jobs-2014.

2 Adam Auriemma, "The Best Jobs of 2014", Wall Street Journal online, 14 April 2014, http://blogs.wsj.com/atwork/2014/04/15/best-jobs-of-2014-congratulationsmathematicians.

3 “2014 Jobs Rated Methodology", http://www.careercast.com/jobs-rated/2014-jobs-rated-methodology.
}

\footnotetext{
${ }^{4}$ Kyle Kensing, "The Worst Jobs of 2014", http://www.careercast.com/jobs-rated/worst-jobs-2014.
} 